\title{
Fungal contamination and aflatoxin content of maize, moringa and peanut foods from rural subsistence farms in South Haiti
}

\author{
Junior Aristil a , Giovanni Venturini ${ }^{\text {b }}$, Giuliana Maddalena ${ }^{\text {b }}$, Silvia Laura Toffolatti ${ }^{\text {b, * }}$, \\ Alberto Spada b \\ a Centre de Recherche Interdisciplinaire pour la Vulgarisation Agricole et le Développement Local (CREIVADEL), Université Notre Dame d'Haiti, Faculté \\ d'Agronomie, BP: HT 8110, Redon, Torbeck, Sud d'Haïti, Haiti \\ ${ }^{\mathrm{b}}$ Dipartimento di Scienze Agrarie e Ambientali, Produzione, Territorio, Agroenergia, Università degli Studi di Milano, via G. Celoria 2, 20133, Milano, Italy
}

\section{A R T I C L E I N F O}

\section{Article history:}

Received 6 September 2019

Received in revised form

11 November 2019

Accepted 28 November 2019

Available online $\mathrm{xxx}$

\section{Keywords:}

Food safety

Secondary metabolites

Developing countries

Mycology

\begin{abstract}
A B S T R A C T
Mycotoxins are toxic, low molecular weight compounds produced by fungi. Among them, aflatoxins are the most carcinogenic and they mainly impact on rural communities of developing countries. The present study supplies data on mycobiota and aflatoxin contamination in the most common food products consumed in Haiti. The study concerns analyses performed on 49 samples of meals and seeds collected in South Haiti and tested for fungal occurrence and aflatoxin content by HPLC-DAD technique. The results revealed that three main fungal genera affected Haitian food products: Aspergillus spp. (Section Flavi and Nigri), followed by Penicillium spp. and Fusarium spp. Aflatoxin was present in more than half of the samples of maize (Zea mays L.) kernels (55\%), maize meal (57\%) and moringa (Moringa oleifera Lam.) seeds (64\%), and in $25 \%$ of peanut (Arachis hypogaea L.) samples. The tested food products were mostly contaminated by aflatoxin $\mathrm{B}_{1}\left(\mathrm{AFB}_{1}\right)$ followed by aflatoxin $\mathrm{B}_{2}\left(\mathrm{AFB}_{2}\right)$, while no aflatoxins type $G$ were detected. The total concentration of aflatoxins in the positive samples was $228 \mu \mathrm{g} / \mathrm{kg}$ on average, i.e., fiftyseven and eleven times higher than the maximum levels allowed in Europe and USA, respectively. Both the presence of aflatoxigenic fungi and aflatoxin contamination in maize kernels seemed to be related to agricultural practices, such as weed control, irrigation and growing cycle length. These findings suggest that the Haitian population is strongly exposed to aflatoxin risk. This risk could be reduced by exploiting simple and accessible farming strategies for minimizing mycotoxin contamination, at least for maize.
\end{abstract}

() 2019 Elsevier Ltd. All rights reserved.

\section{Introduction}

Mycotoxins represent an important threat to human health, particularly in tropical countries that are characterized by high temperature and humidity. Several mycotoxins can be synthesized by different fungal genera, but the most toxic and widespread are aflatoxins, ochratoxins, fumonisins and trichothecenes, produced by members of the genera Aspergillus section Flavi (ASF), Aspergillus section Nigri (ASN), Penicillium (PEN) and Fusarium (FUS) (Williams et al., 2004; Venturini et al., 2011, 2013). A great deal of attention has been given to fungal species belonging to ASF (Varga et al., 2011), because of their ability to produce aflatoxins, which are considered to be one of the most threatening food safety problems worldwide (Kumar et al., 2017).

\footnotetext{
* Corresponding author.

E-mail address: silvia.toffolatti@unimi.it (S.L. Toffolatti).
}

Aflatoxins occur in several chemical forms, mainly aflatoxin $B_{1}$ $\left(\mathrm{AFB}_{1}\right), \mathrm{B}_{2}\left(\mathrm{AFB}_{2}\right), \mathrm{G}_{1}\left(\mathrm{AFG}_{1}\right)$ and $\mathrm{G}_{2}\left(\mathrm{AFG}_{2}\right)$ (Ismail et al., 2018). Among them, $\mathrm{AFB}_{1}$ is the most frequent contaminant of staple foods, and one of the most potent naturally occurring mutagens and carcinogens known. Indeed it is classified as a Group 1 human carcinogen by IARC, the International Agency for Research on Cancer (IARC, 1993). Daily consumption of foods contaminated with $\mathrm{AFB}_{1}$ can result in chronic aflatoxicosis, that causes stunting in children, immunosuppression, cancer, and reduced life expectancy (Shephard, 2008). Moreover, toxic effects of aflatoxin exposure account for more than $40 \%$ of the diseases in developing countries with a short life expectancy (Williams et al., 2004). The risk of human aflatoxicosis is higher in tropical and subtropical countries where, generally, aflatoxin regulations are not in force and crops are consumed without monitoring the mycotoxin content (Shephard, 2008; Wild and Gong, 2010).

Aflatoxigenic fungi and aflatoxins contaminate a number of 
crops, mainly maize (Zea mays L.) and peanuts (Arachis hypogaea L.), but also spices and oilseeds (Amaike and Keller, 2011; Georgiadou et al., 2012; Hammami et al., 2014; Lanier et al., 2009; Strosnider et al., 2006; Wild, 2007). Fungal infection and aflatoxin contamination often begin before harvest, being favored by agronomic practices as well as genotype choice, biotic and abiotic stresses (Shephard, 2008; Wilson et al., 2002). Several field investigations have shown that reduction in abiotic stress, such as drought, weed competition and inadequate plant nutrition, reduces fungal infections and the production of aflatoxins (Guo et al., 2008; Kebede et al., 2012). Contamination caused by species of the genera Aspergillus and Penicillium can also occur under unsuitable storage conditions, where water activity $\left(a_{w}\right)$ drops slightly below 0.95 , promoting the fungal growth of xerophilic species, that are the dominant ones under storage conditions (Mannaa \& Kim, 2017). Various studies have demonstrated that temperature and $a_{w}$ ranges that favor the growth rate of Aspergillus spp. are different from those that enhance the production of aflatoxin. Optimal values for fungal growth are $35{ }^{\circ} \mathrm{C}$ and 0.95 , respectively (Hill et al., 1985). Aflatoxin synthesis has its optimum at $33^{\circ} \mathrm{C}$ and 0.99 (Mannaa \& Kim, 2017). During storage, even crops initially dried to a safe moisture condition can allow aflatoxin contamination if moisture content increases due to insect respiration or localized moisture condensation (Williams et al., 2004).

Crops, such as cereals, oilseeds, legumes, and roots, are particularly exposed to mycotoxin contamination due to the adaptation of mycotoxigenic fungi, such as Aspergillus flavus Link, to warm climates (Battilani et al., 2016). In the past, toxigenic fungal contaminations of maize and maize-derived as well as peanut products were reported in various tropical and subtropical regions and countries such as Latin America (Zorzete et al., 2013), Caribbean (Aristil et al., 2017), Argentina (Astoreca et al., 2011), Brazil (Rocha et al., 2009) and Ecuador (Pacin et al., 2003). In a tropical country, such as Haiti, with widespread subsistence farming and limited storage facilities, fungal growth and mycotoxin contamination may be favored. Indeed, aflatoxin contamination of Haitian maize and peanuts has been reported in a study, where mycotoxin content was determined by using immuno-affinity chromatography and fluorometry techniques (Schwartzbord and Brown, 2015). Aflatoxin exposure was confirmed by monitoring its biomarker in urine samples from Haitian adults and children (Gerding et al., 2015). In a preliminary study carried out on a limited number of maize, moringa (Moringa oleifera Lam.) seeds and peanut samples, high levels of aflatoxin in Haitian crops and foodstuffs together with the occurrence of toxigenic fungi were reported (Aristil et al., 2017).

The main aim of this study was to estimate toxigenic fungi occurrence, with particular attention to ASF, and aflatoxin contamination by HPLC analysis, in 49 Haitian crop samples consisting of maize, moringa, peanut seeds and maize meals supplied from farmers and street markets in the plain of Les Cayes in the Sud Department of Haiti. The effect of agricultural practices on fungal and mycotoxin contamination was evaluated on Haitian maize samples cropped under different conditions. The long-term objective is to set up low cost agricultural and storage practices that could reduce aflatoxin risk in Haitian commodities.

\section{Material and methods}

\subsection{Food sampling and information on agricultural practices carried out in the field}

A total of forty-nine samples of local agricultural products were randomly collected in Southern Haiti (Sud Department, Les Cayes Arrondissement) in August 2015, namely: maize kernels $(n=20)$, maize meals $(n=7)$, moringa seeds $(n=14)$ and peanuts $(n=8)$. All seed samples (not less than $1-2 \mathrm{~kg}$ ) were supplied by farmers and directly withdrawn in the homesteads from the top, the middle and the bottom of storage containers. Meal samples (1-2 kg) were collected at the street markets of Croix de Bossal and Marché au Fer (Les Cayes Arrondissement) from seven different suppliers, following the same seed sampling criteria. During the sampling session, a short inventory about agricultural practices carried out during the maize growing season was established through a model questionnaire, in order to study the possible factors which influence fungal contamination and aflatoxin synthesis in maize kernels. The questions included background information such as growing season length (GSL, expressed in days), fertilization (yes or no), irrigation management (yes or no) and weed control (number of weedings). Individual samples were mixed thoroughly and kept in polythene bags, frozen $\left(-20^{\circ} \mathrm{C}\right)$ for $24 \mathrm{~h}$ to reduce pest activity and transported in refrigerated bags to the Mycology Laboratory at the Department of Agricultural and Environmental Sciences (DiSAA, University of Milan, Milan, Italy), where mycological and toxicological analyses were performed. Three representative subsamples (about $50 \mathrm{~g}$ ) were randomly taken per sample and stored at $4{ }^{\circ} \mathrm{C}$ until analysis.

\subsection{Water activity determination}

Water activity $\left(a_{w}\right)$ in the samples was measured by automatic analysis with AQUALAB CX-2 equipment (Decagon Devices Inc., Pullman, WA, USA). Each sample was measured three times.

\subsection{Fungal isolation}

Fungal isolation was performed as described by Aristil et al. (2017). One hundred kernels or seeds per sub-sample were randomly chosen, surface-sterilized with $\mathrm{NaOCl}(1 \%)$ for $10 \mathrm{~min}$ (Parsa et al., 2016), and rinsed three times in sterile deionized water. After drying on sterile paper, the kernels or seeds were placed on Petri dishes containing sterile half-strength Potato Dextrose Agar (mPDA; PDA, Difco $\left.{ }^{\circledR}\right)$ amended with dichloran $(0.002 \mathrm{~g} / \mathrm{l})$ and broad-spectrum antibiotics (chloramphenicol, $0.1 \mathrm{~g} /$ $\mathrm{L}$; streptomycin sulphate, $0.2 \mathrm{~g} / \mathrm{l}$; neomycin sulphate, $0.12 \mathrm{~g} / \mathrm{l}$ ). Three replicates of nine kernels or seeds were prepared per food sample.

The analysis of toxigenic viable mycobiota from meals was carried out by inoculating the suspension obtained by serial dilution in Petri dishes containing mPDA. Ten grams of meals were homogenized in $90 \mathrm{ml}$ of $0.1 \%$ peptone-water solution (Bacto Peptone Difco $($ ) and mixed by orbital shaking for $30 \mathrm{~min}$. The obtained suspension was serially diluted (1:10) and three replicates consisting of $0.1 \mathrm{ml}$ of suspension were inoculated in three different Petri dishes containing mPDA.

\subsection{Fungal identification}

The inoculated mPDA plates were incubated at $25^{\circ} \mathrm{C}$ in the dark for 5 days and microscopically examined at $20 \times$ magnification (Primo Vert, Zeiss Milano). All the developed fungal colonies were screened according to the macro-morphological and cultural criteria and assigned to different genera by using classical identification methods (Pitt and Hocking, 2009; Samson et al., 2010; Watanabe, 2010). Colonies identified as Aspergillus, Fusarium and Penicillium spp. were selected and purified by monoconidial isolation (Pitt and Hocking, 2009). Identification at section level of monoconidial Aspergillus spp. strains was based on the macro- and micro-morphological criteria (Leslie and Summerell, 2006; Pitt and Hocking, 2009). The fungal isolates were maintained on PDA slants at $4{ }^{\circ} \mathrm{C}$ and as conidial suspensions stored at $-80^{\circ} \mathrm{C}$ in $20 \%$ glycerol 
solution. Data on fungal incidence were recorded as percentage of infected kernels or seeds (isolation frequency of each toxigenic fungal taxon, IF) or as CFU/g (CFU=Colony Forming Unit), for meals. The identification at species level within each toxigenic taxon was not relevant to the aim of the present study.

\subsection{Determination of aflatoxin contamination by HPLC analysis}

About $100 \mathrm{~g}$ of seed samples were milled for $1.5 \mathrm{~min}$ in a laboratory mill (Foss Cyclotec Sample Mill 1093; Foss Italia S.r.l.) set at the finest setting $(1 \mathrm{~mm})$. All ground samples were stored at $-20^{\circ} \mathrm{C}$ in aluminum zipper bags until use. HPLC-grade analytical reagents, such as a sodium chloride $(\mathrm{NaCl})$, potassium bromide $(\mathrm{KBr})$, phosphate buffer saline (PBS) and nitric acid $\left(\mathrm{HNO}_{3}\right)$ solution, and solvents, such as water, methanol and water, were purchased from Merck (Merck KGaA, Darmstadt, Germany). Aflatoxins were quantified following the protocol described by Vega-Rojas et al. (2016) with some modifications. Aflatoxins were extracted following the cereal and nuts protocol of Easi-Extract Aflatoxin Art. No.: RP71/ RP70N (https://food.r-biopharm.com/products/easi-extractaflatoxin-2/; R-Biopharm Rhône, Glasgow, Scotland). Briefly, a subsample $(50 \mathrm{~g})$ of ground samples was placed in $1 \mathrm{~L}$ of $1 \% \mathrm{NaCl}$ and blended for $5 \mathrm{~min}$ in a high-speed blender after adding $100 \mathrm{~mL}$ methanol:water $(80: 20, \mathrm{v} / \mathrm{v})$ solution. Aflatoxins were extracted from moringa and peanuts by blending ground samples in water for $1 \mathrm{~min}$, then adding absolute methanol and blending the mixture for 2 min.

After centrifugation at $4500 \mathrm{~g}$ for $10 \mathrm{~min}$, the supernatant was filtered through a fluted Whatman no. 4 filter paper (GE Healthcare, Milano, Italy). The filtrate ( $5 \mathrm{~mL}$ ) was diluted with $15 \mathrm{~mL} 0.1 \mathrm{M}$ PBS $(\mathrm{pH}=7.4)$. Before PBS dilution, the $\mathrm{pH}$ of peanut filtrates was adjusted to 7.4 value with $2 \mathrm{M}$ sodium hydroxide. The diluted filtrate was purified by a clean-up method through an Easi-Extract Aflatoxin immunoaffinity column (R-Biopharm Rhône) following the manufacturer's instructions. Aflatoxins were recovered in amber glass vials using $1.5 \mathrm{~mL}$ methanol and $1.5 \mathrm{~mL}$ milli-Q water (EMD Millipore, Merck KGaA, Darmstadt, Germany). An aliquot $(100 \mu \mathrm{l})$ of the purified sample was injected into the HPLC system at a flow rate of $1 \mathrm{~mL} \mathrm{~min}{ }^{-1}$. Aflatoxins were quantified using an Agilent 1260 Infinity HPLC system (Agilent Technologies, Cernusco sul Naviglio Milano, Italy) equipped with quaternary pump (G1311B), vacuum degasser (G1379B), autosampler (G1329B), fluorescence detector Agilent 1260 infinity/1200 series (G1321B) and analytical column: Inertsil ODS-3V $(5 \mu \mathrm{m}, 4.6 \times 9150 \mathrm{~mm}$; GL Sciences Inc., Roma, Italy) preceded by a guard cartridge $(10 \times 3.2 \mathrm{~mm}$. i.d., $5 \mu \mathrm{m}$ particle size; Hichrom Ltd, Reading, UK). Analytical and guard columns were maintained at $40{ }^{\circ} \mathrm{C}$. The isocratic mobile phase was a water:methanol $(40: 60, \mathrm{v} / \mathrm{v})$ solution containing $\mathrm{KBr}(0.144 \mathrm{~g})$ and $4 \mathrm{M} \mathrm{HNO}_{3}(420 \mu \mathrm{l})$ in a final volume of $1.2 \mathrm{~L}$. The fluorescence detector was set to analyze the excitation wavelength of $362 \mathrm{~nm}$ and the emission wavelength of $425 \mathrm{~nm}$ for $\mathrm{AFB}_{1}$ and $\mathrm{AFB}_{2}$ and of 455 for $\mathrm{AFG}_{1}$ and $\mathrm{AFG}_{2}$. The content of aflatoxins was determined with a post-column photochemical derivatization electrochemically generated bromine (Kobra ${ }^{\circledR}$ cell, RBiopharm Rhône Ltd), at $100 \mu \mathrm{A}$ setting. Aflatoxin contents were determined comparing peak areas with those obtained from reference solutions of $A F B_{1}, A_{F B}, A F G_{1}$ and $A F G_{2}$. The mixed standards of $\mathrm{AFB}_{1}, \mathrm{AFB}_{2}, \mathrm{AFG}_{1}$ and $\mathrm{AFG}_{2}$ were purchased as Afla standard Solution (Cat No. P22) from R-Biopharm Rhône. The mixture consists of $250 \mathrm{ng} \mathrm{AFB}_{1}, 250 \mathrm{ng} \mathrm{AFB}_{2}, 250 \mathrm{ng} \mathrm{AFG}_{1}$ and $250 \mathrm{ng} \mathrm{AFG}_{2}$ in one $\mathrm{mL}$ methanol. From this standard solution, five calibration solutions $(10,20,40,100$ and $400 \mathrm{ng} / \mathrm{ml})$ were prepared by diluting an aliquot of the stock solution with the appropriate volume of liquid chromatography mobile phase. The standard solutions were stored at $-15^{\circ} \mathrm{C}$, wrapped in aluminum foil (because the analyzed mycotoxins gradually breakdown under UV light), and held for no more than 3 months.

\subsection{Statistical analysis}

The SPSS statistical package for Windows, v. 25 (IBM Italia, Milano), was used for all statistical analyses. Differences in the distribution of the data concerning contamination by the different fungal genera (ASF, ASN, FUS and PEN), expressed as IF or CFU/g, were analyzed by non-parametric statistics: Kruskall-Wallis test and pairwise comparison of the data. Bivariate analysis, used to analyze the correlations between measured variables, was carried out for calculating the Spearman's $\rho$ correlation coefficient with significant two tailed-tests on rank-transformed data. The curves of regression model were calculated in the presence of significant correlation among variables. The $\chi^{2}$ test was used for categorical variables such as fertilization (yes or no), irrigation management (yes or no). The level of significance was set at 0.05 .

\section{Results}

\subsection{Validation of chromatographic method}

The calibration curves reported good linearity $\left(r^{2}>0.995\right)$. The recovery experiments showed that the average recoveries for $\mathrm{AFB}_{1}$, $\mathrm{AFB}_{2}, \mathrm{AFG}_{1}$ and $\mathrm{AFG}$ 2 ranged from 98.3 to $95.1 \%$. The precision was demonstrated by a coefficient of variation (CV) always below $3.5 \%$. For this reason, results were not corrected for recovery. The limit of detection LOD and quantification LOQ were determined by a signalto-noise ratio of 3 and 10, respectively. The method's average LOD for aflatoxins was about $1.2 \mu \mathrm{g} / \mathrm{kg}$ while the average LOQ was calculated as $4.1 \mu \mathrm{g} / \mathrm{kg}$.

\subsection{Mycological analysis of Haitian crops}

Mycological analyses showed variable levels of fungal contamination of the samples by potential toxigenic taxa according to the data distribution and statistical analysis (Fig. 1; Table 1). Maize samples showed different contamination patterns. Maize kernels showed significant differences among the distribution of IF values of the different mycotoxigenic taxa $\left(\chi^{2}=10.6 ; \mathrm{df}=3 ; P=0.014\right)$ (Fig. 1A). Aspergillus spp., and in particular ASF (IF $=48 \%$ ), predominated over the other genera (Table 1). Maize meal samples did not show any significant difference in the distribution of the different fungal genera $\left(\chi^{2}=5.3 ; \mathrm{df}=3 ; P=0.147\right)$. A single sample showed a particularly high contamination by PEN $(1,000,005$ CFU/ g) that, however, was outside from the distribution (extreme outlier) and did not contribute to differentiate the taxa (Fig. 1B). Moringa seeds (Fig. 1C) were significantly more heavily contaminated by Aspergillus spp., with ASF and ASN strains showing average IF values equal to 13 and $23 \%$, respectively (Table 1 ), than by the other fungal genera $\left(\chi^{2}=19.7 ; \mathrm{df}=3 ; P<0.0001\right)$. The fungal strains isolated from peanut seeds (Fig. 1D) were similarly dominated by Aspergillus spp., with IF values equal to 17 and $18 \%$ for ASF and ASN (Table 1 ), respectively $\left(\chi^{2}=12.5 ; \mathrm{df}=3 ; P=0.006\right)$.

\subsection{Water activity, isolation frequency of Aspergillus section Flavi, and aflatoxin contamination}

Results obtained on water activity $\left(a_{w}\right)$, isolation frequency (IF) of ASF strains, aflatoxin content and percentages of contaminated samples of the tested Haitian foodstuff are presented in Table 2. For aflatoxin contamination, only results concerning $\mathrm{AFB}_{1}$ and $\mathrm{AFB}_{2}$ were reported since no AFGs were detected in Haitian food materials. As a consequence, the total aflatoxin content $\left(\mathrm{AF}_{\mathrm{tot}}\right)$ was 
A
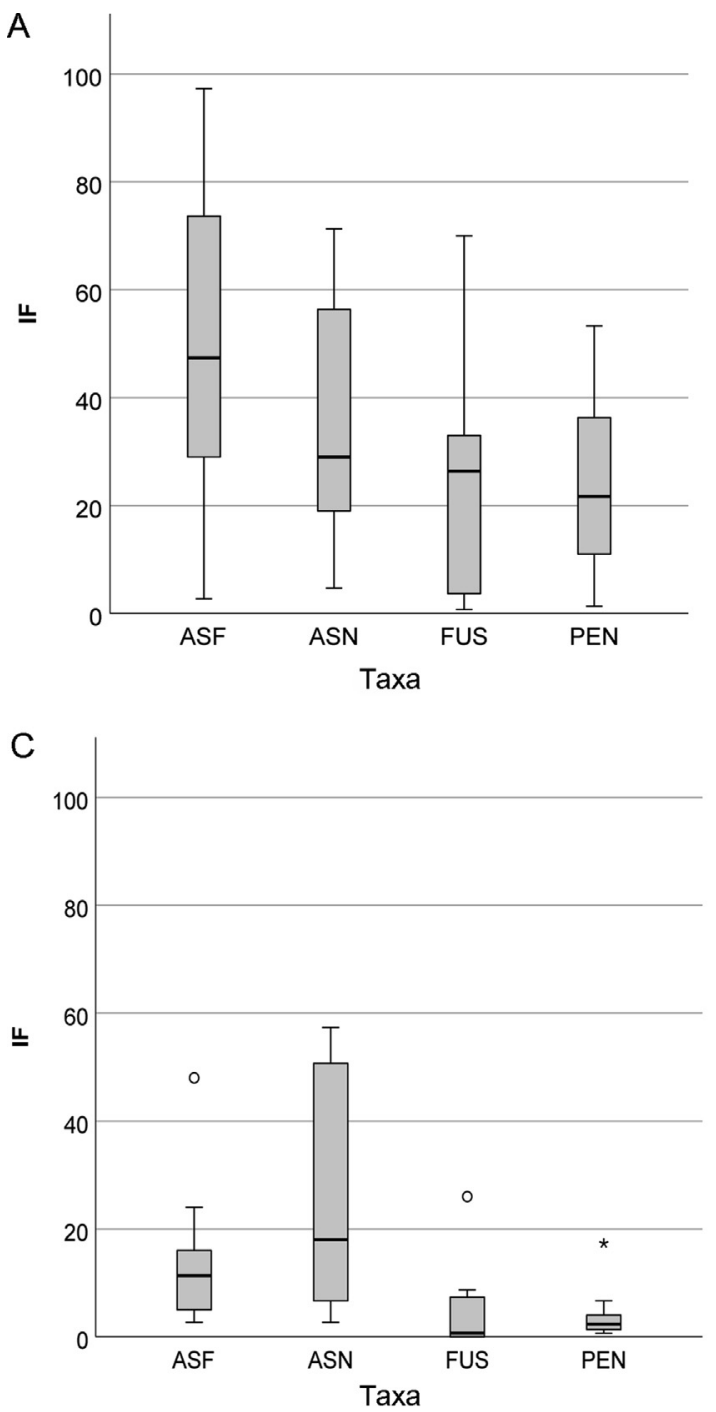

B

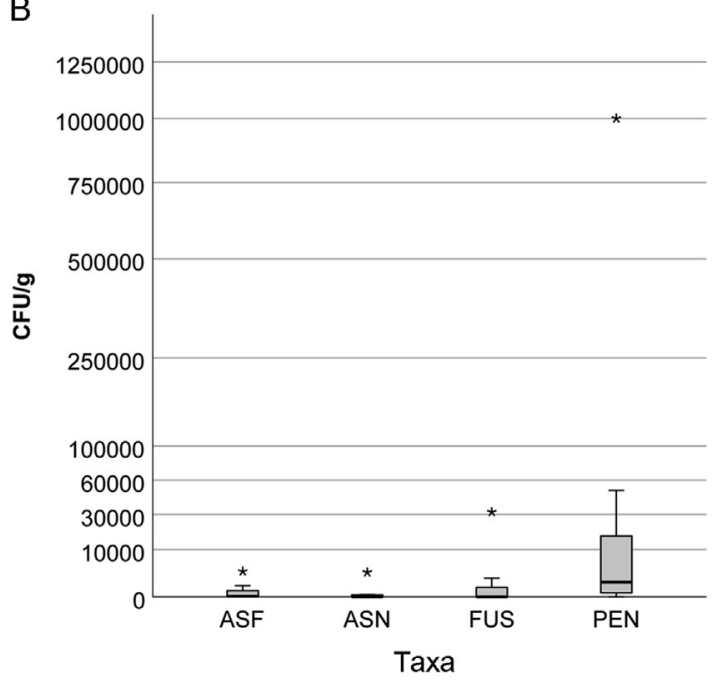

D

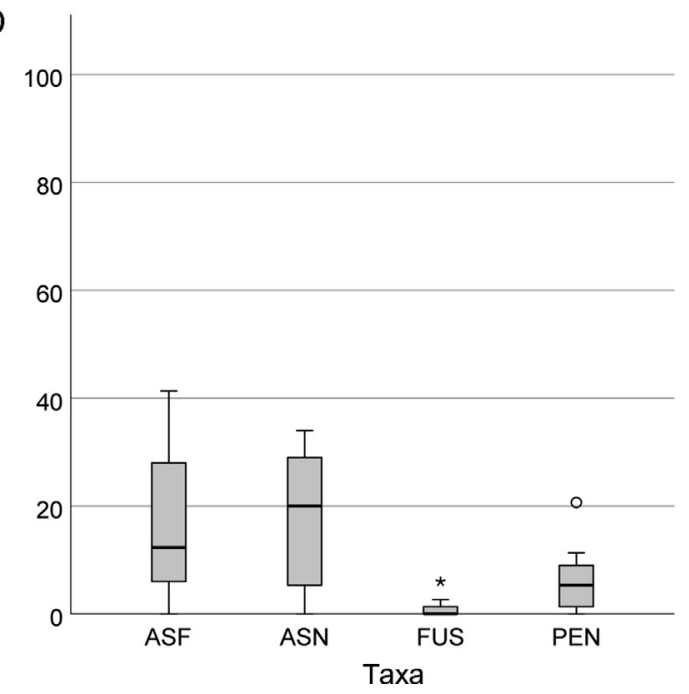

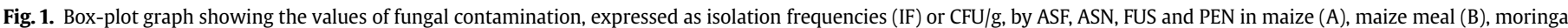

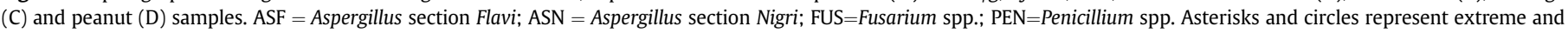
mild outliers, respectively.

Table 1

Average values \pm standard deviation (SD) of isolation frequency (IF) or CFU/g of ASF (Aspergillus Section Flavi), ASN (Aspergillus Section Nigri), FUS (Fusarium spp.) and PEN (Penicillium spp.) in maize, maize meal, moringa and peanut samples and results of statistical analysis (Kruskal-Wallis and pairwise comparison test)*.

\begin{tabular}{llll}
\hline Food sample & Taxon & $\mathrm{IF} \pm \mathrm{SD}$ & CFU/g \pm SD \\
\hline Maize kernels & ASF & $48 \pm 11.9 \mathrm{a}$ & - \\
& ASN & $34 \pm 11 \mathrm{ab}$ & - \\
& FUS & $24 \pm 10.8 \mathrm{~b}$ & - \\
Maize meals & PEN & $25 \pm 10.2 \mathrm{~b}$ & - \\
& ASF & - & $511 \pm 161.3 \mathrm{a}$ \\
& ASN & - & $401 \pm 260.4 \mathrm{a}$ \\
Moringa & FUS & - & $4776 \pm 3815.6 \mathrm{a}$ \\
& PEN & - & $150326 \pm 260348.1 \mathrm{a}$ \\
& ASF & $13 \pm 7.3 \mathrm{a}$ & - \\
Peanuts & ASN & $23 \pm 6.4 \mathrm{a}$ & - \\
& FUS & $4 \pm 2.5 \mathrm{~b}$ & - \\
& PEN & $4 \pm 3.8 \mathrm{~b}$ & - \\
& ASF & $17 \pm 8.2 \mathrm{a}$ & - \\
& ASN & $18 \pm 5.3 \mathrm{a}$ & - \\
& FUS & $1 \pm 1.6 \mathrm{~b}$ & - \\
& PEN & $7 \pm 7.3 \mathrm{ab}$ & - \\
\hline
\end{tabular}

* Different letters correspond to significant differences in the data distribution for $P=0.05$. determined as the sum of $\mathrm{AFB}_{1}$ and $\mathrm{AFB}_{2}$.

\subsubsection{Maize kernels}

The average values of water activity of the samples ranged from 0.6 to 0.8 , with a mean value of 0.7 and a very low value of standard deviation $(\mathrm{SD}=0.04)$. ASF was detected in all samples with variable average isolation frequencies ( $48 \pm 30 \%$ ). The majority $(55 \%)$ of maize kernel samples was contaminated by aflatoxins, with an average aflatoxin content $\left(\mathrm{AF}_{\text {tot }}\right)$ of $186 \pm 304 \mu \mathrm{g} / \mathrm{kg}$. A high variability was found among replicates. Some replicates showed the detectable presence of aflatoxin while others had values below the detection limit. $\mathrm{AFB}_{1}$ content was thirteen times higher than $\mathrm{AFB}_{2}$ level.

\subsubsection{Maize meals}

Maize meals reported $a_{w}$ values ranging from 0.4 to 0.6 , with a mean value of 0.5 , and very low values of standard deviation $(\mathrm{SD}=0.01)$. Almost all samples $(86 \%)$ were simultaneously contaminated by ASF and aflatoxins. The average ASF contamination in maize meal was $514 \pm 363 \mathrm{CFU} / \mathrm{g}$ (Table 2 ), but this value was mainly influenced by a single sample that showed a contamination 
Table 2

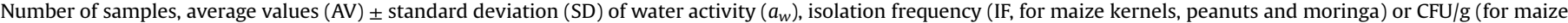

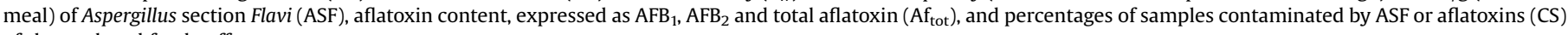
of the analyzed foodstuff.

\begin{tabular}{|c|c|c|c|c|c|}
\hline \multirow[t]{2}{*}{ Parameters } & \multirow[t]{2}{*}{ Values } & \multicolumn{4}{|l|}{ Foodstuff } \\
\hline & & Maize kernels & Maize meal & Moringa & Peanuts \\
\hline Samples & Number & 20 & 7 & 14 & 8 \\
\hline$a_{w}$ & $\mathrm{AV} \pm \mathrm{SD}$ & $0.7 \pm 0.04$ & $0.5 \pm 0.01$ & $0.6 \pm 0.06$ & $0.6 \pm 0.17$ \\
\hline $\mathrm{IF}(\%)$ or $\mathrm{CFU} / \mathrm{g}$ & $\begin{array}{l}\mathrm{AV} \pm \mathrm{SD} \\
\mathrm{CS}\end{array}$ & $\begin{array}{l}48 \pm 30 \\
100\end{array}$ & $\begin{array}{l}514 \pm 363 \\
86\end{array}$ & $\begin{array}{l}13 \pm 12 \\
100\end{array}$ & $\begin{array}{l}17 \pm 14 \\
88\end{array}$ \\
\hline $\mathrm{AFB}_{1}(\mu \mathrm{g} / \mathrm{kg})$ & $\begin{array}{l}\mathrm{AV} \pm \mathrm{SD} \\
\mathrm{CS}\end{array}$ & $\begin{array}{l}172.4 \pm 282.5 \\
55\end{array}$ & $\begin{array}{l}50.8 \pm 47.9 \\
57\end{array}$ & $\begin{array}{l}81.6 \pm 186.4 \\
64\end{array}$ & $\begin{array}{l}58.7 \pm 117.2 \\
25\end{array}$ \\
\hline $\mathrm{AFB}_{2}(\mu \mathrm{g} / \mathrm{kg})$ & $\begin{array}{l}\mathrm{AV} \pm \mathrm{SD} \\
\mathrm{CS}\end{array}$ & $\begin{array}{l}13.5 \pm 21.6 \\
50\end{array}$ & $\begin{array}{l}5.9 \pm 7.2 \\
43\end{array}$ & $\begin{array}{l}8.4 \pm 19.2 \\
36\end{array}$ & $\begin{array}{l}11.5 \pm 22.3 \\
25\end{array}$ \\
\hline $\mathrm{AF}_{\text {tot }}(\mu \mathrm{g} / \mathrm{kg})$ & $\begin{array}{l}\mathrm{AV} \pm \mathrm{SD} \\
\mathrm{CS}\end{array}$ & $\begin{array}{l}185.9 \pm 303.9 \\
55\end{array}$ & $\begin{array}{l}56.7 \pm 54.9 \\
57\end{array}$ & $\begin{array}{l}90.0 \pm 205.6 \\
64\end{array}$ & $\begin{array}{l}70.2 \pm 139.4 \\
25\end{array}$ \\
\hline
\end{tabular}

level of $2950 \mathrm{CFU} / \mathrm{g}$. More than one half of the meal samples (57\%) were contaminated by aflatoxins, with an average amount of $57 \pm 55 \mu \mathrm{g} / \mathrm{kg}$. Both $\mathrm{AFB}_{1}$ and $\mathrm{AFB}_{2}$ were detected in aflatoxin contaminated samples with an $\mathrm{AFB}_{1}$ content nine times higher than $\mathrm{AFB}_{2}$ level. The high values of standard deviation recorded for ASF and aflatoxin contaminations associated with differences among replicates.

\subsubsection{Moringa seeds}

Moringa seeds showed a mean $a_{w}$ value of $0.6 \pm 0.06$. All the samples were contaminated by ASF, with an average isolation frequency of $13 \pm 12 \%$ (Table 2). Aflatoxins, and in particular AFBs, were found in $64 \%$ of moringa samples with an average total aflatoxin contamination of $90 \pm 206 \mu \mathrm{g} / \mathrm{kg}$. It must be pointed out that the samples positive to $\mathrm{AFB}_{1}$ and $\mathrm{AFB}_{2}$ showed total aflatoxin levels ranging from 11.1 to $638.4 \mu \mathrm{g} / \mathrm{kg}$. $\mathrm{AFB}_{1}$ levels were ten times higher than those of $\mathrm{AFB}_{2}$.

\subsubsection{Peanuts}

The water activity of peanuts showed a mean of $0.6 \pm 0.17$ (Table 2). ASF contamination was found in $88 \%$ of the samples with an average isolation frequency of $17 \pm 14 \%$. The majority (75\%) of Haitian peanut samples were negative for aflatoxin presence. The two positive samples showed a total aflatoxin content ranging from 186.6 to $375.1 \mu \mathrm{g} / \mathrm{kg}$, while the average value of the overall peanut samples was $70 \pm 139 \mu \mathrm{g} / \mathrm{kg}$. $\mathrm{AFB}_{1}$ levels were five times higher than those of $\mathrm{AFB}_{2}$.

\subsection{Correlation analysis}

Spearman's $\rho$ nonparametric correlation was used to test a possible correlation among the following quantitative measured variables transformed in ranks: water activity $\left(a_{w}\right)$, isolation frequencies (IF or CFU/g) of Aspergillus section Flavi (ASF) and total aflatoxin content $\left(\mathrm{AF}_{\text {tot }}\right)$.

No correlation was observed between $a_{w}$ and ASF ( $\rho=0.372$, $P=0.106$ for maize kernels; $\rho=-0.22, P=0.635$ for maize meals; $\rho=0.212, P=0.466$ for moringa; $\rho=0.12, P=0.778$ for peanuts) nor between $a_{w}$ and $\mathrm{AF}_{\text {tot }}$ content $(\rho=0.121, P=0.61$ for maize kernels; $\rho=-0.374, P=0.41$ for maize meals; $\rho=-0.306$, $P=0.287$ for moringa; $\rho=0.16, P=0.712$ for peanuts) in all the tested food products.

A significant positive correlation was found between ASF and $\mathrm{AF}_{\text {tot }}$ content of maize meals $(\rho=0.784 ; P=0.036)$. No correlation between the two variables was found in maize kernels $(\rho=0.381$; $P=0.098)$, moringa seeds $(\rho=0.486 ; P=0.078)$ and peanuts $(\rho=0.325 ; P=0.432)$.

The influence of agricultural practices adopted in the field on contamination of maize kernels by $\mathrm{ASF}$, and on $\mathrm{AF}_{\text {tot }}$ levels was investigated. Among the field practices considered, fertilization did not show any association with $\operatorname{ASF}\left(\chi^{2}=0.267 ; \mathrm{df}=1 ; P=0.606\right)$, and $\mathrm{AF}_{\text {tot }}\left(\chi^{2}=0.202 ; \mathrm{df}=1 ; P=0.653\right)$. However, weed management practices had a significant negative correlation $(\rho=-0.476 ; P=0.034)$ with ASF contamination in maize kernels. Indeed, samples collected from fields with the highest frequencies of weeding showed lower levels of ASF contamination (Fig. 2). AF tot showed a significant positive correlation with growing season length (GSL) $(\rho=0.463 ; P=0.04)$ : maize kernels collected from fields with GLS ranging from 90 to 150 days showed a lower distribution of aflatoxin contamination than those collected from fields where GSL was 180 or 210 days (Fig. 3A). Despite $\chi^{2}$ test showed that $\mathrm{AF}_{\text {tot }}$ and irrigation practices were independent variables $\left(\chi^{2}=12 ; \mathrm{df}=11 ; P=0.364\right)$, the distribution of $\mathrm{AF}_{\text {tot }}$ content was higher in samples collected from fields where no irrigation was performed (Fig. 3B).

\section{Discussion}

In this study the mycological analysis of food materials collected in Haiti revealed high levels of contamination by the three major

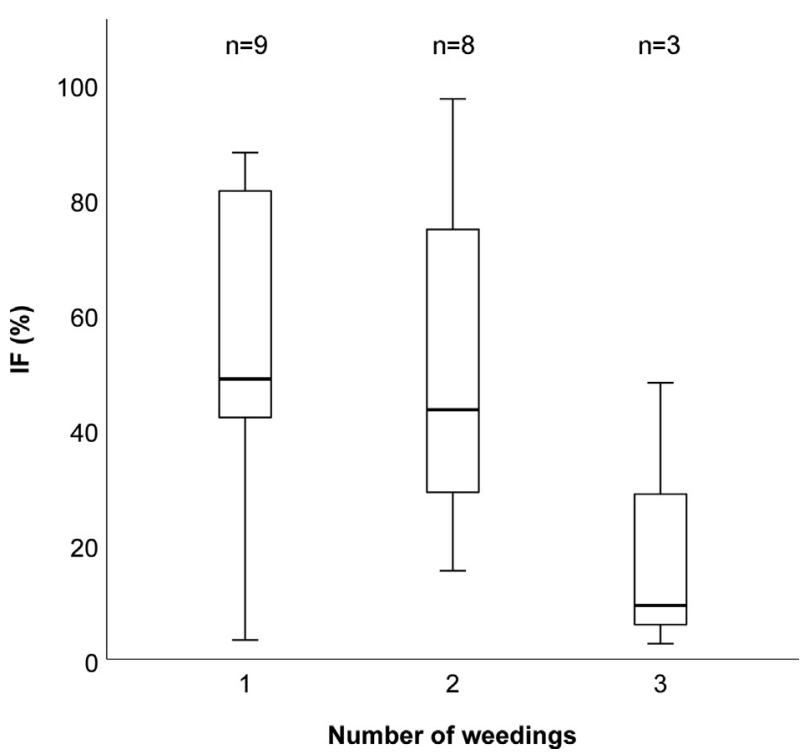

Fig. 2. Box-plot graph showing the distribution of ASF isolation frequencies (IF) on maize kernels according to the number of weeding treatments performed in field ( $\mathrm{n}=$ number of samples). 

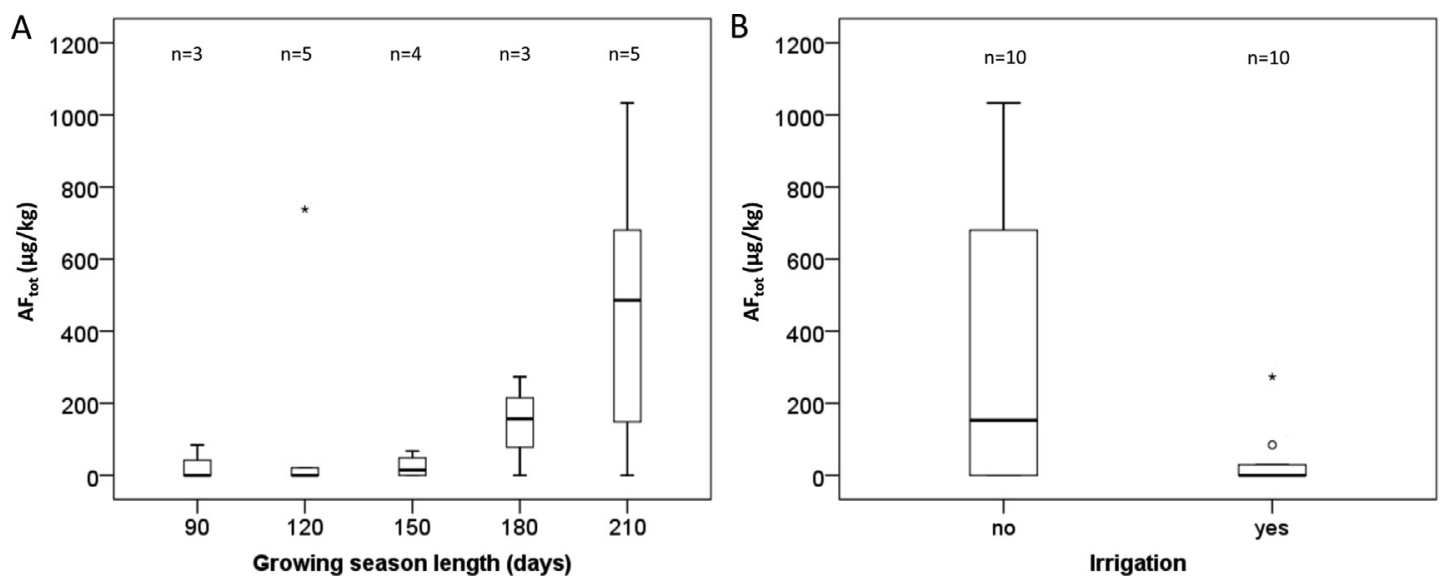

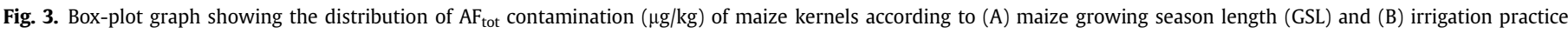
performed in field ( $\mathrm{n}=$ number of samples). Asterisks and circles represent extreme and mild outliers, respectively.

toxigenic fungal genera, Aspergillus, Fusarium and Penicillium, in maize kernels, maize meals, moringa and peanuts. In general, raw materials showed a greater incidence of Aspergillus spp. compared to the other two mycotoxigenic genera, while transformed material (maize meal) had a more equal distribution of the investigated fungal taxa. Even if no significant differences could be found in the distribution of the potentially mycotoxigenic fungi, Penicillium spp. showed a higher frequency in some maize meal samples that should be better investigated by increasing the sample number. The predominance of Penicillium spp. in corn meal mycobiota has been previously found by other authors in association with non-optimal conditions during storage (Garbini et al., 1987; Etcheverry et al., 1999).

The toxigenic mycobiota recorded in Haitian maize kernels and peanut seeds confirmed the well-known existence of favorable conditions for Aspergillus spp. infection in tropical and subtropical latitudes (Klich, 2007; Mudili et al., 2014; Saleemi et al., 2012; Schwartzbord and Brown, 2015; Agbetiameh et al., 2018). Moreover, the results obtained in the present study indicate that moringa can support the growth of aflatoxigenic fungi and can be contaminated by aflatoxins, as observed in a previous study (Aristil et al., 2017) carried out on a lower number of samples.

Both the frequency of contamination by ASF and the biosynthesis of secondary metabolites, including mycotoxins, are significantly influenced by environmental conditions such as $\mathrm{pH}, a_{w}$ and temperature (Belli et al., 2004; Hope et al., 2005; Sultan and Magan, 2010). In the present study, no correlation was found between the isolation frequency of ASF and $a_{w}$ of the food products, probably due to the fact that the water activity of the samples was in most of the cases equal to or lower than 0.7, when the growth of members of ASF, such as Aspergillus flavus, is favored by $\mathrm{a}_{\mathrm{w}}>0.85$ (Liu et al., 2017; Medina et al., 2017). Since the samples showed water activity conditions not favorable to the ASF growth, it is reasonable to assume that the contamination took place in the field. This hypothesis is also corroborated by the fact that the ears of corn in Haiti are traditionally left in the field on the plants after ripening until they are dry, so that they remain throughout this period exposed to unpredictable events, such tropical downpours which may occur daily. However, more information should be collected on the handling conditions from harvest to storage/market, to exclude that contamination occurred at these stages.

A significant, positive, correlation was found between ASF and aflatoxin contamination in maize meal alone. The absence of correlation found with ASF contamination in seeds could be due to the fact that fungal contamination was determined by different methods: direct plating for seeds, with calculation of the percentage of infected seeds, and dilution technique, with calculation of $\mathrm{CFU} / \mathrm{g}$, for maize meal. Since the aflatoxin content was determined on milled samples, it could have been easier to find a correlation between values obtained on meal/flour than on seed/flour.

Concerning aflatoxin contamination, all the positive samples were contaminated by $\mathrm{AFB}_{1}$ and $\mathrm{AFB}_{2}$, to a lesser extent, while no $A F G_{1}$ nor $A F G_{2}$ were detected. $A_{F B}$ is, indeed, confirmed to be the most frequently found aflatoxin in contaminated samples, when the other aflatoxins are generally not reported in the absence of $\mathrm{AFB}_{1}$ (EFSA Panel on Contaminants in the Food Chain (CONTAM), 2018; Joint FAO/WHO Expert Committee on Food Additives, 2017; Kensler et al., 2011). The reports where AFGs concentration is higher than that of AFBs are uncommon (Matumba et al., 2015).

Overall, $50 \%$ of the analyzed food samples were contaminated by aflatoxins, with differences among food types. Aflatoxin contamination was found in $55 \%$ of the maize kernel samples, with $\mathrm{AFB}_{1}$ mean values of $172 \mu \mathrm{g} / \mathrm{kg}$. The European Union (EU) (Commission Regulation (EC) No 1881/2006) and FDA in USA (https:// www.fda.gov/regulatory-information/search-fda-guidancedocuments/guidance-industry-action-levels-poisonous-ordeleterious-substances-human-food-and-animal-feed) established that the limits for aflatoxin contamination in food for human consumption are 4 and $20 \mu \mathrm{g} / \mathrm{kg}$, respectively. The aflatoxin content of the contaminated maize kernels was above the European and American limits in 55\% of the samples, indicating the chronic exposure of Haitian people to aflatoxins. This can have negative effects on human health, due to the widespread consumption of locally produced maize by Haitian consumers, that every day ingest $50 \mathrm{~g}$ of maize (Ranum et al., 2014).

Maize meals demonstrated the lowest accumulation of $\mathrm{AFB}_{1}$, with a mean of $51 \mu \mathrm{g} / \mathrm{kg}$, that could be associated with the reduced presence of Aspergillus spp. over Fusarium spp. and Penicillium spp. in the mycobiota. Indeed, a significant positive correlation between aflatoxin content and ASF contamination was found in these samples. However, in this case all the positive samples (57\% of the total number of food products) showed aflatoxin levels far above the European and American food security levels $\left(15<\mathrm{AF}_{\text {tot }}<166 \mu \mathrm{g} / \mathrm{kg}\right)$.

Moringa was the food sample most contaminated by the mycotoxins compared with the others. As a matter of fact, $64 \%$ of moringa samples were positive for aflatoxin at different concentrations. Remarkably, in two samples the content of aflatoxin exceeded the limit established by the European Union $(4 \mu \mathrm{g} / \mathrm{kg})$ by 125 and 160 times. This is particularly worth noticing, since moringa is used as a nutraceutical ingredient in baby food (Aristil, pers. 
comm.) and as a panacea for various diseases (Leone et al., 2015; Baptista et al., 2017). Therefore, aflatoxin contamination in moringa is a serious threat for Haitian consumers.

Peanuts were the least contaminated samples, since only $25 \%$ of them showed aflatoxin occurrence, even if over the safety limits (27 and $119 \mu \mathrm{g} / \mathrm{kg}$ ). These results are in line with those reported in hot and humid regions by other authors (Abdel-Hadi et al., 2010; Ding et al., 2015; Mupunga et al., 2014; Pitt and Hocking, 2006).

The high standard deviation values found in ASF contamination and aflatoxin content could be due to the differences found among replicates: contaminated particles can be, in fact, heterogeneously distributed throughout a lot. This constitutes a technical problem for any sampling method and it is frequently encountered when determining contamination by mycotoxigenic fungi and mycotoxin content (Whitaker, 2006; Maestroni and Cannavan, 2011). Increasing sample and subsample sizes, and the number of aliquots quantified could help to reduce the variability associated with the mycotoxin test procedure in future studies (Whitaker, 2006).

Aflatoxins are accumulated both pre- and post-harvest, in the latter case when food is stored under conditions that promote fungal growth (Wild and Gong, 2010; Logrieco and Moretti, 2008; Mahuku et al., 2019; Torres et al., 2014). The pre-harvest control of fungal and mycotoxin contamination is based on good agricultural practices aiming at reducing crop stresses such as drought (Mutiga et al., 2017) and weed competition. The results obtained in this study suggest that agricultural practices may indeed have a role in fungal and mycotoxin contamination. Maize kernels coming from fields where no weeding and no irrigation were performed exhibited the highest ASF and aflatoxin contamination, respectively. These results are also in agreement with the findings by Mutiga et al. (2017), who reported that water stress affected maize ear and kernel development, and in turn influenced susceptibility to fungal colonization and aflatoxin content. However, due to the low number of samples $(\mathrm{n}=3)$ where three weedings were performed in the field, further investigations are needed to confirm the results obtained on the weed control.

The other agronomic parameter found to be linked with aflatoxin content in maize was the growing season length. In Haiti, only two local maize varieties are cultivated and prolonged drying of maize kernels in the field after physiological maturity occurs. This delayed harvest increases insect damage, fungal growth and aflatoxin contamination. As reported by Kaaya et al. (2005), aflatoxin levels increased 4-fold and more than 7-fold when maize harvest was delayed by 3 and 4 weeks, respectively, after maturity. Therefore, particular attention should be taken to this important aspect for the prevention of aflatoxin contamination in the field, by proposing a simple good agricultural practice: drying of the seeds after harvest, without leaving the ear on the plant. Experimental activities aiming at evaluating the most suitable protocol to be followed by the farmers for drying the seeds are planning stages. Fertilization in the present investigation did not affect aflatoxin contamination, although a correlation was previously reported between a balanced $\mathrm{N}$ fertilizer and lower mycotoxin contamination (Blandino et al., 2008).

In conclusion, the present study has provided information about toxigenic mycobiota and the quantity of aflatoxins that contaminate foodstuff coming from the most important farming region of Haiti for the production of maize, peanuts and moringa. The results obtained on the mycobiota characterization highlight the necessity of characterizing the fungal mycobiota at the species level and further investigating Haitian samples for the occurrence of other important mycotoxins, such as ochratoxin A, fumonisins and trichothecenes. A higher number of samples is moreover needed to confirm the findings of this work, especially in relation to agricultural practices. These preliminary results confirm the problem of food safety in developing countries and the necessity of adopting practicable and effective good agronomic practices in a country with limited facilities. The approaches that can reduce exposure to a significant degree require a coordinated effort in terms of education and raising awareness at all levels of Haitian society, taking into account local conditions and traditions, including good agricultural practices and post-harvest management. The response, however, needs to be a concerted one, including international agencies, governments and non-governmental organizations, to share the need for a global harmonization of mycotoxin legislation and to minimize the unequal access to safe and sufficient food.

\section{Declaration of competing interest}

The authors declare that they have no known competing financial interests or personal relationships that could have appeared to influence the work reported in this paper.

\section{Acknowledgements}

This study was undertaken in the frame of a project (IFAH AQUAPLUS) aiming at assessing the prevalence of aflatoxins in agricultural commodities of Haiti, in order to target and prioritize simple agricultural practices for the prevention of aflatoxin contamination. Deep thanks to the staff of Agriculture Faculty of Université Notre Dame d'Haiti for their sincere collaboration. Particularly, Sanon Pierre Jonas, Tessa Jean Baptiste and Perles Marie Georguette, who have contributed to the work summarized in this manuscript. The authors wish to thank Prof. Alberto Schiraldi (University of Milan) and Dr. Gemma Assante for their critical reading of the manuscript, Piero Attilio Bianco, Patrizia de Nisi and Giorgio Lucchini for the support during the analyses.

This work was supported by the Italian Waldensian Church (8x1000); the NGO AVSI Foundation; CISV; and from Rotary Club of Les Cayes and Milan.

\section{Appendix A. Supplementary data}

Supplementary data to this article can be found online at https://doi.org/10.1016/j.jspr.2019.101550.

\section{References}

Abdel-Hadi, A., Carter, D., Magan, N., 2010. Temporal monitoring of the nor-1 (aflD) gene of Aspergillus flavus in relation to aflatoxin $\mathrm{B}_{1}$ production during storage of peanuts under different water activity levels. J. Appl. Microbiol. 109, 1914-1922.

Agbetiameh, D., Ortega-Beltran, A., Awuah, R.T., Atehnkeng, J., Cotty, P.J., Bandyopadhyay, R., 2018. Prevalence of aflatoxin contamination in maize and groundnut in Ghana: population structure, distribution, and toxigenicity of the causal agents. Plant Dis. 102, 764-772.

Amaike, S., Keller, N.P., 2011. Aspergillus flavus. Annu. Rev. Phytopathol. 49, 107-133.

Aristil, J., Venturini, G., Spada, A., 2017. Occurrence of toxigenic fungi and aflatoxin potential of Aspergillus spp. strains associated with subsistence farmed crops in Haiti. J. Food Prot. 80, 626-631.

Astoreca, A.L., Dalcero, A.M., Pinto, V.F. Vaamonde, G. 2011. A survey on distribution and toxigenicity of Aspergillus section Flavi in poultry feeds. Int. J. Food Microbiol. 146, 38-43.

Baptista, A.T.A., Silva, M.O., Gomes, R.G., Bergamasco, R., Vieira, M.F., Vieira, A.M.S. 2017. Protein fractionation of seeds of Moringa oleifera Lam. and its application in superficial water treatment. Separ. Purif. Technol. 180, 114-124.

Battilani, P., Toscano, P., Van der Fels-Klerx, H.J., Moretti, A., Camardo Leggieri, M., Brera, C., Rortais, A., Goumperis, T., Robinson, T., 2016. Aflatoxin B 1 contamination in maize in Europe increases due to climate change. Sci. Rep. 6, 24328.

Belli, N., Marin, S., Sanchis, V., Ramos, A.J., 2004. Influence of water activity and temperature on growth of isolates of Aspergillus section Nigri obtained from grapes. Int. J. Food Microbiol. 96, 19-27.

Blandino, M., Reyneri, A., Vanara, F., 2008. Influence of nitrogen fertilization on mycotoxin contamination of maize kernels. Crop Protect. 27, 222-230.

Ding, X., Wu, L., Li, P., Zhang, Z., Zhou, H., Bai, Y., Chen, X., Jiang, J., 2015. Risk assessment on dietary exposure to aflatoxin $\mathrm{B}_{1}$ in post-harvest peanuts in the yangtze river ecological region. Toxins $15,4157-4174$.

EFSA Panel on Contaminants in the Food Chain (CONTAM), 2018. Effect on public 
health of a possible increase of the maximum level for 'aflatoxin total' from 4 to $10 \mu \mathrm{g} / \mathrm{kg}$ in peanuts and processed products thereof, intended for direct human consumption or use as an ingredient in foodstuffs. EFSA J. 16, 5175.

Etcheverry, M., Nesci, A., Barros, G., Torres, A., Chulze, S., 1999. Occurrence of Aspergillus section Flavi and aflatoxin $\mathrm{B}_{1}$ in corn genotypes and corn meal in Argentina. Mycopathologia 147, 37-41.

Garbini, A., Galli, S., Tomchinsky, E., Delli Santi, V., Gandía, S., Rizzo, J., Varsavsky, E., Frade, H., 1987. ). Aflatoxinas: control en alimentos a base de harina de maíz. Julio. Presented at 2nd Congreso Latinoamericano de Micotoxicología, Maracay, Venezuela.

Georgiadou, M., Dimou, A., Yanniotis, S., 2012. Aflatoxin contamination in pistachio nuts: a farm to storage study. Food Control 26, 580-586.

Gerding, J., Ali, N., Schwartzbord, J., Cramer, B., Brown, D.L., Degen, G.H., Humpf, H.U., 2015. A comparative study of the human urinary mycotoxin excretion patterns in Bangladesh, Germany, and Haiti using a rapid and sensitive LC-MS/MS approach. Mycotoxin Res. 31, 127-136.

Guo, B., Chen, Z., Lee, R.D., Scully, B.T., 2008. Drought stress and preharvest aflatoxin contamination in agricultural commodity: genetics, genomics and proteomics. J. Integr. Plant Biol. 50, 1281-1291.

Hammami, W., Fiori, S., Al Thani, R., Kali, N.A., Balmas, V., Migheli, Q., Jaoua, S., 2014. Fungal and aflatoxin contamination of marketed spices. Food Control 37, $177-181$.

Hill, R.A., Wilson, D.M., McMillian, W.W., Widstrom, N.W., Cole, R.J., Sanders, T.H., Blankenship, P.D., 1985. Ecology of the Aspergillus flavus group and aflatoxin formation in maize and groundnut. In: Lacey, J. (Ed.), Trichothecenes and Other Mycotoxins. Wiley \& Sons, Chichester, pp. 79-95.

Hope, R., Aldred, D., Magan, N., 2005. Comparison of the effect of environmental factors on deoxynivalenol production by F. culmorum and F. graminearum. Lett. Appl. Microbiol. 40, 295-300.

IARC, 1993. Aflatoxins. In: IARC Monographs on the Evaluation of Carcinogenic Risks to Humans - Some Naturally Occurring Substances:. Food Items and Constituents, Heterocycles Azoaromatic Amines and Mycotoxins, vol. 56 IARC, Lyon, pp. 245-396.

Ismail, A., Gonçalves, B.L., de Neeff, D.V., Ponzilacqua, B., Coppa, C.F.S.C., Hintzsche, H., Sajid, M., Cruz, A.G., Corassin, C.H., Oliveira, C.A.F., 2018. Aflatoxin in foodstuffs: occurrence and recent advances in decontamination. Food Res. Int. $113,74-85$.

Joint FAO/WHO Expert Committee on Food Additives, 2017. Evaluation of Certain Contaminants in Food: Eighty-Third Report of the Joint FAO/WHO Expert Committee on Food Additives. WHO Press, Geneva (Chapter 3).

Kaaya, A.N., Warren, H.L., Kyamanywa, S., Kyamuhan, W., 2005. The effect of delayed harvest on moisture content, insect damage, moulds and aflatoxin contamination of maize in Mayuge district of Uganda. J. Sci. Food Agric. 85, 2595-2599.

Kebede, H., Abbas, H.K., Fisher, D.K., Bellaloui, N., 2012. Relationship between aflatoxin contamination and physiological responses of corn plants under drought and heat stress. Toxins 4, 1385-1403.

Kensler, T.W., Roebuck, B.D., Wogan, G.N., Groopman, J.D., 2011. Aflatoxin: a 50-year odyssey of mechanistic and translational toxicology. Toxicol. Sci. 120 (Suppl. 1), S28-S48.

Klich, M.A., 2007. Aspergillus flavus: the major producer of aflatoxin. Mol. Plant Pathol. 8, 713-722.

Kumar, P., Mahato, D.K., Kamle, M., Mohanta, T.K., Kang, S.G., 2017. Aflatoxins: a global concern for food safety, human health and their management. Front. Microbiol. 7, 2170.

Lanier, C., Heutte, N., Richard, E., Bouchart, V., Lebailly, P., Garon, D., 2009. Mycoflora and mycotoxin production in oilseed cakes during farm storage. J. Agric. Food Chem. 57, 1640-1645.

Leone, A., Spada, A., Battezzati, A., Schiraldi, A., Aristil, J., Bertoli, S., 2015. Cultivation, genetic, ethnopharmacology, phytochemistry and pharmacology of Moringa oleifera leaves: an overview. Int. J. Mol. Sci. 16, 12791-12835.

Leslie, J.F., Summerell, B.A., 2006. The Fusarium Laboratory Manual. Blackwell Publishing, Ames, IA.

Liu, X., Guan, X., Xing, F., Lv, C., Dai, X., Liu, Y., 2017. Effect of water activity and temperature on the growth of Aspergillus flavus, the expression of aflatoxin biosynthetic genes and aflatoxin production in shelled peanuts. Food Control $82,325-332$.

Logrieco, A.F., Moretti, A., 2008. Between emerging and historical problems: an overview of the main toxigenic fungi and mycotoxin concerns in Europe. In: Leslie, J.F., Bandyopadhyay, R., Visconti, A. (Eds.), Mycotoxins: Detection Methods, Management, Public Health and Agricultural Trade. CABI, Wallingford, pp. 139-153.

Maestroni, B., Cannavan, A., 2011. Sampling strategies to control mycotoxins. In: De Saeger, S. (Ed.), Determining Mycotoxins and Mycotoxigenic Fungi in Food and Feed. Woodhead Publishing, Sawston, pp. 3-36.

Mannaa, M., Kim, K.D., 2017. Influence of temperature and water activity on deleterious fungi and mycotoxin production during grain storage. Mycobiology 45, 240-254.

Mahuku, G., Nziokib, H.S., Mutegic, C., Kanampiuc, F., Narrodd, C., Makumbie, D., 2019. Pre-harvest management is a critical practice for minimizing aflatoxin contamination of maize. Food Control 96, 219-226.

Matumba, L., Sulyok, M., Njoroge, S.M.C., Njumbe Ediage, E., Van Poucke, C., De Saeger, S., Krska, R., 2015. Uncommon occurrence ratios of aflatoxin $B_{1}, B_{2}, G_{1}$, and $G_{2}$ in maize and groundnuts from Malawi. Mycotoxin Res. 31, 57-62.

Medina, A., Gilbert, M.K., Mack, B.M., Obrian, G.R., Rodríguez, A., Bhatnagarb, D., Payne, G., Magan, N., 2017. Interactions between water activity and temperature on the Aspergillus flavus transcriptome and aflatoxin $\mathrm{B}_{1}$ production. Int. J. Food Microbiol. 256, 36-44.

Mudili, V., Siddaih, C.N., Nagesh, M., Garapati, P., Naveen Kumar, K., Murali, H.S., Yli Mattila, T., Batra, H.V., 2014. Mould incidence and mycotoxin contamination in freshly harvested maize kernels originated from India. J. Sci. Food Agric. 94, $2674-2683$.

Mupunga, I., Lebelo, S.L., Mngqawa, P., Rheeder, J.P., Katerere, D.R., 2014. Natural occurrence of aflatoxins in peanuts and peanut butter from Bulawayo, Zimbabwe. J. Food Prot. 77, 1814-1818.

Mutiga, S.K., Morales, L., Angwenyi, S., Wainaina, J., Harvey, J., Das, B., Nelson, R.J., 2017. Association between agronomic traits and aflatoxin accumulation in diverse maize lines grown under two soil nitrogen levels in Eastern Kenya. Field Crop. Res. 205, 124-134.

Pacin, A.M., González, H.H.L., Etcheverry, M., Resnik, S.L., Vivas, L., Espin, S., 2003. Fungi associated with food and feed commodities from Ecuador. Mycopathologia 156, 87-92.

Parsa, S., García-Lemos, A.M., Castillo, K., Ortiz, V., López-Lavalle, L.A.B., Braun, J., Vega, F.E., 2016. Fungal endophytes in germinated seeds of the common bean, Phaseolus vulgaris. Fungal Biol. 120, 783-790.

Pitt, J.I., Hocking, A.D., 2006. Mycotoxins in Australia: biocontrol of aflatoxin in peanuts. Mycopathologia 162, 233-243.

Pitt, J.I., Hocking, A.D., 2009. Fungi and Food Spoilage, third ed., vol. 519. Springer; New York.

Ranum, P., Peña-Rosas, J.P., Garcia-Casal, M.N., 2014. Global maize production, utilization, and consumption. Ann. N. Y. Acad. Sci. 1312, 105-112.

Rocha, L.O., Nakai, V.K., Braghini, R., Reis, T.A., Kobashigawa, E., Corrêa, B., 2009. Mycoflora and co-occurrence of fumonisins and aflatoxins in freshly harvested corn in different regions of Brazil. Int. J. Mol. Sci. 10, 5090-5193.

Saleemi, M.K., Khan, M.Z., Ahrar, K.H.A.N., Javed, I., Ul Hasan, Z., Hameed, M.R., Hameed, S., Mehmood, M.A., 2012. Occurrence of toxigenic fungi in maize and maize-gluten meal from Pakistan. Phytopathol. Mediterr. 51, 219-224.

Samson, R.A., Houbraken, J., Thrane, U., Frisvad, J.C., Andersen, B., 2010. Food and Indoor Fungi, CBS Laboratory Manual Series 2. CBS-Fungal Biodiversity Centre, Utrecht, Netherlands.

Schwartzbord, J.R., Brown, D.L., 2015. Aflatoxin contamination in Haitian peanut products and maize and the safety of oil processed from contaminated peanuts. Food Control 56, 114-118.

Shephard, G.S., 2008. Impact of mycotoxins on human health in developing countries. Food Addit. Contam. A 25, 146-151.

Strosnider, H., Azziz-Baumgartner, E., Banziger, M., Bhat, R.V., Breiman, R., Brune, M.-N., DeCock, K., Dilley, A., Groopman, J., Hell, K., Henry, S.H., Jeffers, D., Jolly, C., Jolly, P., Kibata, G.N., Lewis, L., Liu, X., Luber, G., McCoy, L., Mensah, P., Miraglia, M., Misore, A., Njapau, H., Ong, C.-N., Onsongo, M.T.K., Page, S.W., Park, D., Patel, M., Phillips, T., Pineiro, M., Pronczuk, J., Schurz Rogers, H., Rubin, C., Sabino, M., Schaafsma, A., Shephard, G., Stroka, J., Wild, C., Williams, J.T., Wilson, D., 2006. Workgroup report: public health strategies for reducing aflatoxin exposure in developing countries. Environ. Health Perspect. 114, 1898-1903.

Sultan, Y., Magan, N., 2010. Mycotoxigenic fungi in peanuts from different geographic regions of Egypt. Mycotoxin Res. 26, 133-140.

Torres, A.M., Barros, G.G., Palacios, S.A., Chulze, S.N., Battilani, P., 2014. Review on pre- and post-harvest management of peanuts to minimize aflatoxin contamination. Food Res. Int. 62, 11-19.

Varga, J., Frisvad, J.C., Samson, R.A., 2011. Two new aflatoxin producing species, and an overview of Aspergillus section Flavi. Stud. Mycol. 69, 57-80.

Vega-Rojas, L.J., Carvajal-Moreno, M., Rojas-Molina, I., Rojo-Callejas, F., RuizVelasco, S., Rodriguez-Garcia, M.E., 2016. The Effect of maize germ on the presence of aflatoxins in corn flours treated with a thermo-alkaline process. J. Microb. Biochem. Technol. 8, 408-414.

Venturini, G., Assante, G., Toffolatti, S.L., Vercesi, A., 2011. Mating behavior of a Northern Italian population of Fusarium verticillioides associated with maize. J. Appl. Genet. 52, 367-370.

Venturini, G., Assante, G., Toffolatti, S.L., Vercesi, A., 2013. Pathogenicity variation in Fusarium verticillioides populations isolated from maize in northern Italy. Mycoscience 54, 285-290.

Watanabe, T., 2010. Pictorial Atlas of Soil and Seed Fungi: Morphologies of Cultured Fungi and Key to Species. CRC Taylor and Francis, Boca Raton, FL.

Whitaker, T.B., 2006. Sampling foods for mycotoxins. Food Addit. Contam. 23, $50-61$.

Wild, C.P., 2007. Aflatoxin exposure in developing countries: the critical interface of agriculture and health. Food Nutr. Bull. 28, S372-S380.

Wild, C.P., Gong, Y.Y., 2010. Mycotoxins and human disease: a largely ignored global health issue. Carcinogenesis 31, 71-82.

Williams, J.H., Phillips, T.D., Jolly, P.E., Stiles, J.K., Jolly, C.M., Aggarwal, D., 2004. Human aflatoxicosis in developing countries: a review of toxicology, exposure, potential health consequences, and interventions. Am. J. Clin. Nutr. 80, 1106-1122.

Wilson, D.M., Mubatanhema, W., Jurjevic, Z., 2002. Biology and ecology of mycotoxigenic Aspergillus species as related to economic and health concerns. In: DeVries, J., Trucksess, M.W., Jackson, L.S. (Eds.), Mycotoxins and Food Safety. Kluwer Academic/Plenum Publishers, New York, pp. 3-17.

Zorzete, P., Baquião, A.C., Atayde, D.D., Reis, T.A., Gonçalez, E., Corrêa, B., 2013. Mycobiota, aflatoxins and cyclopiazonic acid in stored peanut cultivars. Food Res. Int. 52, 380-386. 